\title{
KAPABILITAS KEPEMIMPINAN KEPALA SEKOLAH DALAM \\ MENINGKATKAN MUTU PENDIDIKAN DI MADRASAH \\ TSANAWIYAH AL-IHSANIYAH DESA SARANG BURUNG \\ KECAMATAN JAMBI LUAR KOTA KABUPATEN MUARO JAMBI
}

\author{
Sobirin \\ Fakultas Tarbiyah \\ Pendidikan Agama Islam \\ Institut Agama Islam Sulthan Thaha Saifuddin Jambi
}

\begin{abstract}
ABSTRAK
Permasalahan yang diteliti pada tulisan ini adalah tentang Kapabilitas Kepemimpinan Kepala Sekolah Dalam Meningkatkan Mutu Pendidikan di Madrasah Tsanawiyah Al-Ihsaniyah Desa Sarang Burung Kecamatan Jambi Luar Kota Kabupaten Muaro Jambi, dengan tujuan untuk Untuk mengetahui bagaimana pelaksanaan kegiatan Kelapa Sekolah dalam meningkatkan mutu pendidikan di Madrasah Tsanawiyah Al-Ihsaniyah dan Untuk mengetahui apa saja kendala yang dihadapi Kepala Sekolah dalam peningkatan mutu pendidikan di Madrasah Tsanawiyah Al-Ihsaniyah serta upaya apa saja yang dilakukan dalam menghadapi kendala yang dihadapi serta Untuk mengetahui bagaimana mutu yang dihasilkan dari proses Kepemimpinan Kepala Sekolah dan standar apa yang digunakan untuk mengukur mutu pendidikan di Madrasah Tsanawiyah Al-Ihsaniyah.

Penelitian yang penulis lakukan bersifat deskriptif kualitatif dengan objek penelitian yaitu kepala sekolah, guru, dan siswa. Berdasarkan hasil penelitian dan pembahasan yang telah dipaparkan pada bab-bab terdahulu maka hasil penelitian dapat dirumuskan dalam kesimpulan Kepala Sekolah Madarasah Tsanawiyah ALIhsaniyah Desa Sarang Burung telah mampu melaksanakan pengembangan mutu pendidikan yang di Madrasah tersebut dengan bukti pengimplementasian kinerja berupa pelaksanaan perencanaan, pengorganisasian, pengarahan kegiatan sekolah dan melakukan pengawasan yang baik terhadap proses, kinerja dan hasil kegiatan pendidikan di Madrasarh Tsanwiyah Al-Ihsaniyah Desa Sarang Burung. langkahlangkah yang ditempuh oleh Kepala Sekolah Madrasah Tsanawiyah AlIhsaniyah Desa Sarang Burung dalam meningkatkan mutu pendidikan adalah dengan menjalankan fungsi-fungsi educator, menager, administrator, supervisor, leader, inovator dan motivator.
\end{abstract}

Kata Kunci : Kapabilitas, Kemampuan, Kepala Sekolah, Mutu, Pendidikan 


\begin{abstract}
The problems examined in this paper are the Principal Leadership Capability in Improving the Quality of Education in Madrasas Tsanawiyah Al-Ihsaniyah Sarang Burung Village Jambi Luar Kota District, Muaro Jambi Regency, with the aim to find out how the Coconut School activities in improving the quality of education in Madrasah Tsanawiyah Al-Ihsaniyah and To find out what are the obstacles faced by the Principal in improving the quality of education in Madrasah Tsanawiyah AlIhsaniyah and what efforts are being made in dealing with the obstacles faced and To find out how the quality is generated from the Principal Leadership process and what standards used to measure the quality of education in Madrasah Tsanawiyah Al-Ihsaniyah.

The research that the author did was descriptive qualitative with the object of research namely the principal, teacher, and students. Based on the results of the research and discussion presented in the previous chapters, the results of the study can be formulated in the conclusions of the Madarasah Principal Tsanawiyah ALIhsaniyah Bird Nest Village has been able to carry out the development of quality education in Madrasahs with evidence of implementation in the form of planning, organizing, directing school activities and monitoring well the process, performance and results of educational activities at Madrasarh Tsanwiyah AlIhsaniyah Bird Nest Village. the steps taken by the Principal of Madrasah Tsanawiyah AlIhsaniyah Sarang Burung Village in improving the quality of education is by carrying out educator functions, menager, administrators, supervisors, leaders, innovators and motivators.
\end{abstract}

Keywords: Capability, Ability, Principal, Quality, Education.

\section{Latar Belakang}

Dalam dunia pendidikan

sekarang kita melihat banyak usaha

yang dilakukan oleh pemerintah

seperti hal-hal yang berkaitan dengan

Undang-undang Pendidikan

Nasional, Usaha peningkatan dana

Pendidikan, perubahan Kurikulum.

Hal tersebut diharapkan dapat memecahkan pendidikan, dan juga diharapkan tercitnya hal yang positif bagi peningkatan pendidikan. Bila melihat lebih spesifik dan kita tinjau dari sudut lulusan maka output sekolah adalah lulusan yang dapat memberi mamfaat, maka dari itu Upaya penyelenggaraan pendidikan formal yang bermutu sangat diperlukan dan ini sangat berkaitan erat dengan 
kejelian dan ketepatan dalam mengidentifikasikan program operasional pendidikan. Ini berarti bahwa kemampuan manajerial kepala sekolah dan layanan profesional tenaga pendidikan sangat di perlukan dan dapat difungsikan secara optimal.

Oleh karena itu sekolah sebagai unit kerja terdepan yang langsung berhubungan dengan kebutuhan yang nyata di bidang pendidikan, sudah saatnya untuk memiliki kecakapan, serta kemapuan kerja dalam menjalankan program di sekolahnya. Di bawah kepemimpinan kepala sekolah yang profesional, mereka diharapkan mampu menampilkan dan mengembangkan diri sesuai dengan potensinya yang pada gilirannya dapat meningkatkan mutu pendidikan di Institusinya. Dengan demikian kepercayaan masyarakat terhadap lembaga pendidikan formal menjadi semakin meningkat.

Pendidikan merupakan hal yang sangat penting karena pendidikan salah satu penentu mutu Sumber Daya Manusia. Dimana dewasa ini keunggulan suatu bangsa tidak lagi ditandai dengan melimpahnya kekayaan alam, melainkan pada keunggulan Sumber Daya Manusia (SDM), karena mutu Sember Daya Manusia (SDM) berkorelasi positif dengan mutu pendidikan. Hal ini searah dengan Tujuan Pendidikan Nasional pada Bab II, Pasal 3 :

Pendidikan nasional berfungsi mengembangkan kemampuan dan watak serta peradaban bangsa yang bermatabat dalam rangka mencerdaskan kehidupan bangsa, bertujuan berkembangnya potensi peserta didik agar menjadi manusia yang beriman dan bertakwa kepada Tuhan Yang Maha Esa, berakhlak mulia, berilmu, cakap, kreatif, mandiri dan menjadi warga Negara 
yang demokratis serta bertanggung jawab. ${ }^{1}$

Karen itu sangat diperlukan Lembaga atau Instutusi pendidikan yang bermutu yang pada giliran nya menghasilkan lulusan yang bermutu pula. Karena “...pendidikan itu merupakan suatu proses yang bertujuan. setiap proses yang bertujuan tentunya mempunyai ukuran atau yardstick sudah sampai mana perjalana kita dalam mencapai tujuan tersebut."2 Proses dan hasil dari pendidikan itulah yang akan menjawab apakah Lembaga atau Institusi itu bermutu, karena antara proses dan hasil pendidikan saling berhubungan. Akan tetapi agar proses yang baik itu tidak salah arah, maka mutu harus dirumuskan lebih dahulu oleh sekolah, dan harus jelas target

1 Redaksi Sinar Grafika, Undang-undang Sisdiknas ( sistem Pendidikan Nasional ) 2003 (UU RI RI. NO. 20 Th. 2003 ), Jakarta: Rajawali Pers, 2006, hlm. 5-6 yang akan dicapai untuk setiap tahun atau kurun waktu tertentu dan berabagai input dan proses harus selalu mengacu pada mutu (output) yang ingin dicapai. Dengan kata lain tanggung jawab sekolah dalam pengembangan bukan hanya pada proses, tetapi juga bertanggung jawab pada hasil yang dicapai.

$$
\text { Merupakan sesuatu yang }
$$
mustahil, pendidikan atau sekolah menghasilkan lulusan yang bermutu, jika tidak melalui proses pendidikan yang bermutu pula. Merupakan sesuatu yang mustahil pula, terjadi proses pendidikan yang bermutu jika tidak didukung oleh faktor-faktor penunjang proses pendidikan yang bermutu pula.

Proses pendidikan yang bermutu harus didukung oleh personalia, seperti Administrator, guru, dan tata usaha yang bermutu dan professional.

\footnotetext{
2 .H.A.R. Tilaar, Standarisasi Pendidikan Nasion/ Suatu Tinjauan Kritis, Jakarta: Rineka Cipta, 2006, hlm. 75
} 
Hal tersebut didukung pula oleh sarana dan prasarana pendidikan, fasilitas, media, sumber belajar yang memadai, baik mutu maupun jumlahnya, dan biaya yang mecukupi, menajemen yang tepat, serta lingkungan yang mendukung. ${ }^{3}$

Tidak di ragukan lagi setiap orang menghendaki mutu pendidikan yang tinggi. Tetapi dunia pendidikan tidak bisa ditutup-tutupi, pada kenyataannya masih banyak pendidikan yang bermutu rendah dan sekolah-sekolah yang tidak dikelolah dengan baik dan tidak memiliki visi, misi, serta tujuan yang jelas. Banyak faktor yang munkin melatar belakangi hal tersebut. Selain kurang nya faktor sarana dan fasilits, juga karena faktor kepemimpinan yang berkaitan dengan kemampuan (kapabilitas) Kepala Sekolah tersebut. Keprihatinan sekolah seperti ini cukup beralasan karena keterbatasn-keterbatasan yang

\footnotetext{
${ }^{3}$.Nana Syaodih Sukmadinata, dkk, Pengendalian Mutu Sekolah Menengah (Konsep, Prinsip, dan
}

dihadapi dan perhatian dari pemerintah yang dikarenakan alasanalasan tertentu hingga terbatas pula eksistensi sekolah tersebut untuk menjadi sekolah yang berprestasi dan bermutu. Tetapi terlepas dari itu semua bagaimana peran, usaha serta upaya kepala sekolah sebagai seseorang yang bertanggung jawab atas mutu pada suatu pendidikan serta bertanggung jawab terhadap segala sesuatu yang terjadi dilingkungan sekolah. Jika sekolahnya berkonotasi negatif, maka imbasnya kepada kepala Sekolah dan semua pihak yang ada dalam Sekolah itu, dan begitu pula sebaliknya, tatapi tidak hanya itu yang diperlukan kerjasama seluruh elemen yang ada disekolah harus ikut bagian dalam rangka pencapai tujuan pendidikan tersebut. 
Untuk tmewujudkan sekolah yang berprestasi sebenarnya menuntut keterlibatan semua pihak. Akan tetapi, yang menjadi posisi kunci (key pisition) adalah Kepala Sekolah, karena bagamanapun sebaiknya kualitas input (kualitas siswa masuk), guru yang professional dan berprestasi, sarana dan fasiltas yang menunjang, lingkungan masyarakat yang mendukung,dan pengajaran yang baik, tidak akan banyak memberi andil dan mewujudkan sekolah yang berprestasi, karena sebenarnya yang menjadi penentu kebijakan di sekolah tersebut adalah Kapala Sekolah. ${ }^{4}$

Madrasah Tsanawiyah Al-

Ihsaniyah Merupakan lembaga pendidikan Agama yang mengkaji Ilmu-ilmu Agama serta Ilmu-ilmu sosial lainya. Sekarang Madrasah Tsanawiyah Al-Ihsaniyah Desa Sarang burung dipimpin oleh kepala sekolah yang bisa dikatakan belum cukup lama dalam meniti karir sebagai seorang guru dan sebagai seorang pemimpin, sebagaimana diketahui bahwa pada dasar teorinya

${ }^{4}$.Mukhtar dkk, Sekolah Berprestasi, Jakarta : Nimas Multima 2001, hlm. 6 pengalaman juga merupakan faktor yang amat penting yang dibutuhkan dalam memimpin. Meki tidaklah merupakan harga mati bahwa pengalaman merupakan satu-satunya faktor penentu keberhasilan kepemimpinan.

Dalam hal ini Faktor pengalaman akan sangat mempengaruhi keprofesionalan kepala sekolah, terutama terutama dalam mendukung terbentuknya pemahaman tenaga kependidikan terhadap pelaksanaan tugasnya. Pengalaman semasa menjadi guru, menjadi wakil kepala sekolah atau menjadi anggota organisasi kemasyarakatan sangat mempengaruhi kemampuan kepala sekolah dalam melaksanakan pekerjaannya, demikian halnya pelatihan dan penataran yang pernah dilakukan. ${ }^{5}$

Salama GranTour yang dilakukan oleh peneliti ada beberapa hal positif yang telah dilakukan oleh Kepala sekolah Madrasah Tsanawiyah -Al-Ihsaniyah yang merupakan "Progress" dari

\footnotetext{
5 .E.Mulyasa, Menjadi Kepala sekolah Profesional, Bandung : Remaja Rosda Karya 2007, hlm. 100
} 
Kepemimpinannya, seperti dalam bidang Administrasi, sarana dan prasarana serta ada banyak hal yang kiranya harus dibenahi, ditingkatkan, serta di awasi. Hal demikian tidaklah memberi indikasi bahwa kinerja yang dilakukan oleh Kepala Sekolah Madrasah Tsanawiyah Al-Ihsaniyah tersebut telah sesuai dengan tugasnya sebagai kepala sekolah serta apakah telah menunjjukan kemampuannya dalam meciptakan mutu pendidikan yang baik di Madrasah Tsanawiyah Al-Ihsaniyah Desa Sarang Burung.

Berdasarkan latar belakang yang telah di paparkan diatas, maka penulis tertarik untuk mengadakan penelitian di Madrasah Tsanawiyah Al-Ihsaniyah Desa Sarang Burung melalui karya ilmiah berbentuk skripsi dengan judul: Kapabilitas Kepemimpinan Kepala Sekolah Dalam Meningkatkan Mutu
Pendidikan di Madrasah

Tsanawiyah Al-Ihsaniyah Desa

Sarang Burung Kecamatan Jambi

Luar Kota Kabupaten Muaro

Jambi

Permasalahan

1. Bagaimana pelaksanaan kegiatan Kepala Sekolah dalam meningkatkan mutu pendidikan di Madrasah Tsanawiyah AlIhsaniyah?

2. Apa saja kendala yang dihadapi Kepala Sekolah dalam peningkatan mutu pendidikan di Madrasah Tsanawiyah AlIhsaniyah serta upaya apa saja yang dilakukan dalam menghadapi kendala yang dihadapi?

3. Bagaimana mutu yang dihasilkan dari proses kepemimpinan Kepala Sekolah dan standar apa yang digunakan untuk mengukur mutu pendidikan di Madrasah Tsanawiyah Al-Ihsaniyah

\section{Pokok Bahasan}

Para ahli menajemen telah banyak mengemukakakn pengertian kepemimpinan dalam berbagai 
pandangan yang berbeda satu sama lain, perlu di kemukakan berbagai pendapat para ahli tentang pengertian kepemimpinan sebagai dasar konseptual dalam membahas kapabilitas kepemimpinan Kapala Sekolah Madrasah Tsanawiyah AlIhsaniyah di Desa Sarang Burung. Sebelumnya penulis sedikit ingin memberi pengertian mengenai arti kata "Kapabilitas" itu sendiri. Di dalam kamus kata serapan "Kapabilitas berasal dari bahasa Inggris yaitu "capability" yang mana asal katanya yaitu "capabel" yang mempunyai arti "Mampu" yang kemudian ditambah atau digabungkan dengan kata "ity" yang mempunai arti "Hal-hal" atau "Keadaan"” jadi dapat di simpulkan bahwa arti dari kata

\footnotetext{
${ }^{6}$.Surawan Martinis, Kamus Kata Serapan, Jakarta : Gramedia Pustaka Utama 2001, hlm. 280

${ }^{7}$.Hendiyat Soetopo \& Wasty Soemanto, Kepemimpinan dan Supervisi
}

"kapabilitas" itu sendiri adalah "Kemampuan"

Hendiyat Soetopo dan Wasty Soemanto bependapat bahwa "...kepemimpinan adalah suatu usaha kegiatan dalam membimbing suatu kelompok sedemikian hingga/rupa sehingga tecapai tujuan dari kelompok itu yaitu tujuan bersama." ${ }^{7}$ Sedangkan menurut Oteng Sutisna yang Menegaskan mengenai kepemimpinan "...Kepemimpinan dirumuskan sebagai proses mempengaruhi kegiatan seseorang atau kelompok dalam usaha-usaha kearah pencapaian tujuan dalam situasi tertentu". ${ }^{8}$

Ditegaskan lagi oleh Oemar Hamalik mengenai pengertian kepemimpinan $\quad$ "...Kepemimpinan

Pendidikan, Jakarta : Bina Aksara 1988, hlm. 1

8 .Oteng Sutisna, Administrasi Pendidikan Dasar Teoritis Untuk Praktek Profesional, Bandung : Penerbit Angkasa, 1983, hlm. 256 
adalah suatu proses mempengaruhi orang lain atau kelompok agar mereka berbuat untuk mencapai tujuan yang telah ditentukan." 9

$$
\text { Berdasarkan }
$$

pegertian

kepemimpinan tersebut dapat ditarik kesimpulan bahwa dalam kepemimpinan melibatkan interaksi antara dua orang atau lebih dan adanya proses mempengaruhi secara sengaja terhadap bawahan guna mencapi tujuan bersama dan dalam setiap kepemimpinan terdapat (Leader) sebagai orang yang mempengaruhi, dan ada pengikut (Follower) sebagai Pihak yang dipengaruhi, serta adanya tujuan yang hendak dicapai.

$$
\text { Untuk lebih jauh nya }
$$
pemahaman mengenai Kepemimpinan Kepala sekolah, maka

\footnotetext{
9 .Oemar Hamalik, Menajemen Pengembangan Kurikulum, Bandung : Remaja Rosda Karya 2006, hlm.174
}

penulis akan memaparkan pengertian Kepala Sekolah itu Sendiri agar kita dapat memahami apa yang dimaksud dengan Kepemimpinan Kepala Sekolah itu sendiri.

Mukhtar dkk dalam bukunya yang berjudul Sekolah Berprestasi mengemukan mengenai Pengertian dari Kepala sekolah. "...kepala sekolah merupakan orang yang bertanggung jawab penuh terhadap berhasil tidaknya sekolah dalam mewujudkan sekolah yang berkualitas dan berprestasi." 10

Defenisi lain mengenai Kepala sekolah itu sendiri dapat kita lihat dari keterangan kalimat berikut ini:

Dua kata tersebut adalah "Kepala"dan "Sekolah" kata "Kepala" dapat diartiakan "ketua" atau "Pemimpin" dalam suatu Organisasi atau suatu lembaga. Sedangkan "Sekolah" adalah sebuah lembaga dimana menjadi tempat penerima dan memberi pelajaran. Dengan demikian

${ }^{10}$.Mukhtar dkk, op. cit,. hlm. 65 
secara sederhana Kepala Sekolah dapat didefenisikan sebagai seorang tenaga fungsional guru yang diberi tugas untuk memimpin suatu sekolah di mana diselenggarakan proses belajar mengajar, atau tempat di mana terjadi interaksi antara guru yang memberi pelajaran dan murid menerima pelajaran. ${ }^{11}$

"Kepala Sekolah adalah orang yang bertanggung jawab terhadap pelaksanaan pendidikan sekolah, termasuk di dalamnya adalah penanggung jawab pelaksanaan administrasi sekolah." 12

Dari uraian Kontekstual mengenai kepemimpinan dan kepala sekolah diatas maka penulis dapat memahami mengenai Kepemimpinan Kepala Sekolah yaitu "Usaha sadar yang dilakukan dilakukan oleh orang yang mempunyai kedudukan tertinggi disekolah dalam mempengaruhi pengikutnya (Follower) terhadap hal yang berkaitan dengan kegiatan

\footnotetext{
${ }^{11}$.Wahjosumidjo, Kepemimpinan Kepala Sekolah, Jakarta : Rajawali Pers 200, hlm. 83 12

http://www.ditplb.or.id/profile.php?id=54, 24/12/2008
}

sekolah dan pengembangan mutu pendidikan yang merupakan tujuan bersama"

Dalam mengelola sekolah, Kepala Sekolah memiliki peran yang sangat besar. Kepala Sekolah merupakan motor penggerak, penentu arah kebijakan menuju sekolah dan pendidikan secara luas "Kemampuan kepemimpianan kepala sekolah merupakan faktor penentu utama pemberdayaan guru dan peningkatan mutu proses dan produk pembelajaran. Kepala adalah orang yang paling bertanggung jawab apakah staf sekolah dapat bekerja secara optimal." ${ }^{13}$ Sebagai pengelola institusi satuan pendidikan, Kepala Sekolah dituntut untuk selalu meningkatkan efektifitas kinerjanya.

\footnotetext{
${ }^{13}$.Sudarwan Danim, Menjadi Komunitas belajar, Jakarta : Bumi Aksara, 2003, hlm. 197
} 
Untuk mencapai mutu sekolah yang efektif, Kepala Sekolah dan seluruh staff sekolah harus bahu-membahu berkerja sama dengan penuh kekompakan dalam segala hal, Oleh karenanya, Kepala Sekolah perlu memiliki pengetahuan yang baik tentang perencanaan, pengorganisasian, pelaksanaan, dan pengawasan suatu program sekolah dan pendidikan secara luas karena tugas kepala sekolah selaku Pemimpin adalah sebagai “...EMASLIM yaitu educator, menager, administrator, supervisor, leader, inovator dan motivator."14

Untuk lebih rinci mengenai tugas kepala sekolah selaku EMASLIM dapat diuraikan sebagai berikut :

1. Kepala Sekolah Sebagai Educator
Kepala Sekolah sebagai educator/Pendidik bermakna sebagai sebuah proses pembentukan karakter yang didasari nilai-nilai dari Esensi Pendidikan.

Sebagai educator Kepala sekolah harus senaniasa berupaya meningkatkan kualitas pembelajaran yang dilakukan oleh para guru. ${ }^{15}$

2. Kepala Sekolah sebagai Menager Kepala Sekolah sebagai Manajer bermakna adalah seluruh kemampuan dalam mengelola sumber daya untuk mencapai tujuan institusi pendidikan secara efektif dan efisien melalui fungsi - fungsi manajerial.

Dalam rangka melakukan peran dan fungsinya sebagai menajer, kepala sekolah harus memiliki strategi yang tepat untuk memberdayakan tenaga kependidikan melalui kerjasama atau kooperatif, memberi kesempatan kepada para tenaga kependidikan untuk meningkatkan profesinya, dan mendorong keterlibatan seluruh tenaga kependidikan dalam berbagai

${ }^{15}$.E.Mulyasa, op, cit, hlm. 100

${ }^{14}$.Mukhtar dkk op,cit. hlm. 15, 
kegiatan yang menunjang program sekolah. ${ }^{16}$

3. Kepala Sekolah sebagai

\section{Administrator}

Kepala Sekolah sebagai

Administrator bermakna Kepala

Sekolah adalah insan yang mengatur

Sistem Administrasi.

"Kepala sekolah sebagai
administrator memiliki hubungan
yang sangat erat dengan berbagai
aktifitas pengelolahan administrasi
yang bersifat pencatatan, penyusunan
dan pendokumenan seluruh program
sekolah"17
4. Kepala Sekolah rebagai
Supervisor
Kepala
Supervisor adalah upaya-upaya
dalam $\quad$ membantu

mengembangkan profesionalitas guru.
"Kepala sekolah sebagai supervisor harus mewujudkan dalam kemampuan menyusun, melaksanakan program supervis pendidikan, serta memamfaatkan hasilnya"18

5. Kepala Sekolah sebagai Leader Kepala Sekolah sebagai Leader/Pemimpin , adalah upayaupaya untuk mempengaruhi orangorang untuk bekerjasama mencapai tujuan.

"Kepala sekolah sebagai Leader harus mampu memberikan petunjuk dan pengawasan, meningkatkan kemauan mengajar tenaga kependidikan, membuka komunikasi dua arah, dan mendelegasika tugas" ${ }^{19}$ 6. Kepala Sekolah sebagai Inovator Kepala Sekolah sebagai Inovator adalah pribadi yang dinamis 
dan kreatif, yang tidak terjebak pada

suatu rutinitas.

Dalam rangka peran dan fungsinya sebagai Inovator, kepala sekolah harus memiliki strategi yang tepat untuk menjalin hubungan yang harmonis dengan lingkungan, mencari gagasan baru, mengintegrasikan setiap kegiatan, memberi teladan kepada seluruh tenaga kependidikan disekolah, dan mengembangkan model-model pemebelajaran yang inovatif. $^{20}$

7. Kepala Sekolah sebagai Motivator Kepala Sekolah bertindak sebagai Motivator adalah Kemampuan memberi dorongan agar seluruh komponen pendidikan dapat berkembang secara professional. ${ }^{21}$

Sebagai motivator, kepala sekolah memiliki strategi yang tepat untuk memberikan motivasi kepada tenaga kependidikan dalam melakukan berbagai tugas dan fungsinya. ${ }^{22}$

\footnotetext{
${ }^{20}$ Ibid. hlm.118

21

http://manajerialpendidikan.blogspot .com/2008/02/kepala-sekolajsebagai-emasli amatmosfir.html, 22/12/2008
}

Seorang pemimimpin juga

harus memiliki kemampuan :

a. Conceptual : ( Pemahaman luas tentang sekolah sebagai organisasi terbuka, manajemen , teknologi pendidikan, pembelajaran, organisasi pembelajar )

b. Transpormasional Mentransformasikan visi bersama dalam karya nyata, menumbuhkan sensitivitas sekolah milik bersama, mengubah potensi sumber daya dalam karya nyata )

c. Entrepreneurship : ( Merangsang sumber daya sekolah untuk berkreasi, bernegosiasi, bekerja sama untuk menghasilkan hasrat bagi sekolah. Mendorong spirit untuk berani mengambil resiko )

d. Technical : ( Menguasai ketrampilan manajerial, mengerti proses, prosedur dan strategi menjadi organisasi pembelajar )

$$
\text { Human Being Process : ( }
$$

Memberdayakan, mendorong, mesugesti, menumbuhkan dan membangun kepercayaan warga sekolah ). ${ }^{23}$

\footnotetext{
22 Ibid. hlm.120

${ }^{23}$ http://akhmadsudrajat (ed).files.wordpress.com/2007/11/le adership.ppt, 20/12/2008, hlm. 19
} 


\section{Metode Penelitian}

Penelitian yang penulis lakukan bersifat deskriptif kualitatif dengan objek penelitian yaitu kepala sekolah, guru, dan siswa. Penelitian ini mengkaji permasalahan Kemampuan Kepala Sekolah dalam peningkatan Mutu pendidikan di MTs ALIhsaniyah Desa Sarang Burung yang mana peneliti akan melihat kemampuan Kepala sekolah MTs AlIhsaniyah Desa Sarang Burung sebagai pemimpin di sekolah tersebut. Penulis akan melakukan penelitian menggunakan instrumen pengumpulan data yang meliputi observasi, wawancara, dan dokumentasi.

Sumber data yang menyangkut dengan persoalan yang diahadapi pada penelitian ini adalah diperoleh langsung dari sumber pertama yakni ; (1) Kepala MTs Al-Ihsaniyah Desa Sarang Burung (2) Guru MTs Al-
Ihsaniyah Desa Sarang Burung (3) Kepala TU dan Siswa MTs AlIhsaniyah Desa Sarang Burung. Sebagai informan kunci / informan penentu dalam penelitia ini adalah Kepala Sekolah MTs AlIhsaniyah Desa Sarang Burung. Dari kepala sekolah tersebut akan diperoleh informasi sesuai dengan kebutuhan penelitian. Kemudian dari Kepala Sekoah akan diperoleh informasi tantang guru yang juga dijadikan informan. Dari kepela sekolah akan diperoleh informasi tentang fungsi-fungsi Menajemen yang dilakukan untuk meningkatkan mutu Pendidikan.

Dalam pegambilan sampel dapa penelitian ini adalah menggunakan snowball sampling. Menrut Lee dan Berg sebagaimana yang dikutip oleh Iskadar “... Strategi dasar teknik bola salju (snowball) ini dimulai dengan 
menetapkan satu atau beberpa

informan kunci (key informants). ${ }^{24}$

Dalam pengumpulan data

peneliti menggunakan metode

Observasi, wawancara, serta

dokumentasi, karena “...Jenis metode

yang dipilih dan digunakan dalam

pengumpulan data, tentunya harus

sesuai dengan sifat dan karakteristik

penelitian yang dilakukan."25

Sugiyono mengungkapkan

mengenai pengertian analisi data

“...adalah proses mencari dan

menyusun secara sistematis data yang

diperoleh dari hasil wawancara,

catatan lapangan, dan dokumentasi,

dengan cara mengorganisasikan data

ke dalam kategorisasikan data

kedalam ketegori, menjabarkan ke

dalam unit-unit, melakukan sintesa,

menyusun ke dalam pola, memilih mana yang penting dan yang akan

dipelajari, dan membuat kesimpulan

sehingga mudah difahami oleh diri sendiri maupun orang lain." 26

Selanjutnya

Iskandar

menyebutkan “...Analisi data

penelitian data Kualitatif, dapat dilakukan melalui langkahlangkah,sebagai berikut: (1) reduksi data; (2) display/penyajian data; dan, (3) mengambil kesimpulan."27 Jadi, untuk melaukukan analisis data peneliti menggunakan Analisis sebagai berikut:

\section{Kesimpulan}

Berdasarkan hasil penelitian dan pembahasan yang telah dipaparkan pada bab-bab terdahulu maka hasil penelitian dapat dirumuskan dalam kesimpulan :

Aplikasi, Bumi Akasara : Jakrta 2006 , hlm.171-172

${ }^{25}$.Nurul Zariah, Metodologi Penelitian Sosial dan Pendidikan Teori dan
${ }^{26}$.Sugiyono, op.cit., hlm. 244

${ }^{27}$.Iskandar, op.cit., hlm. 222 
1. Kepala Sekolah Madarasah Tsanawiyah AL-Ihsaniyah Desa Sarang Burung telah mampu melaksanakan pengembangan mutu pendidikan yang di Madrasah tersebut dengan bukti pengimplementasian kinerja berupa pelaksanaan perencanaan, pengorganisasian, pengarahan kegiatan sekolah dan melakukan pengawasan yang baik terhadap proses, kinerja dan hasil kegiatan pendidikan di Madrasarh Tsanwiyah Al-Ihsaniyah Desa Sarang Burung.

2. langkah-langkah yang ditempuh oleh Kepala Sekolah Madrasah Tsanawiyah Al-Ihsaniyah Desa Sarang Burung dalam meningkatkan mutu pendidikan adalah dengan menjalankan fungsi-fungsi educator, menager, administrator, supervisor, leader, inovator dan motivator.

3. Bentuk dan kendala yang dihadapi oleh Kepala Sekolah Madrasa Tsanawiyah Al-Ihsaniyah Desa sarng burung adalah kurangnya budaya membaca para siswa, kurangnya pemamfaatan perpustakaan dan kurang atau minimnya sarana dan prasarana pembelajaran yang ada di Madarasah Tsanawiyah AlIhsaniyah Desa Sarng Burung. usaha yang dilakukan kepala sekolah dalam mengatasi kendala itu adalah dengan peningkatan kerjasama dengan guru, peningkatan profesionalitas guru, peningkatan kesejahteraan guru, usaha peningkatan sarana dan prasarana pembelajaran 


\section{Daftar Pustaka}

Anonim, (2004), Metodologi

Penulisan Skripsi, Jambi: IAIN STS Jambi.

-----, (2004), Pedoman Menajemen Berbasis Madrasah, Depdiknas Jambi.

Aan Komaria dan Cepi Triatna, (2008), Visionary Leadership Menuju Sekolah efektif, Jakarta: Bumi Aksara.

Abdul Gaffar, Dasar-dasar Administrasi dan Supervisi Pengajaran, Jakarta: Anagkasa Raya.

H.A.R. Tilaar, (2006), Standarisasi Pendidikan Nasionl Suatu Tinjauan Kritis, Jakarta: Rineka Cipta.

http://akhmadsudrajat.files.wordpress. com/2007/11/leadership.ppt,

$21 / 12 / 2008$

http://media.diknas.go.id/media/docu

$\underline{\text { ment/4153.pdf, 20/12/2008 }}$

http://manajerialpendidikan.blogspot.

com/2008/02/kepala-sekolaj-

sebagai-emasli matmosfir.html,

$22 / 12 / 2008$ http://one.indoskripsi.com/node/3895

, 22/12/2008

http://www.ditplb.or.id/profile.php?i

$\underline{\mathrm{d}=54}, 24 / 12 / 2008$

http://www.puskur.net/inc/si/050Per

men_13_2007_Stdr-KepSek.pdf.,

$25 / 12 / 2008$

http://www.geocities.com/guruvalah/

Manaj_Pening_Mutu_Pend.html,

$25 / 12 / 2008$

Hendiyat Soetopo \& Wasty Soemanto, (1988), Kepemimpinan dan Supervisi Pendidikan, Jakarta: Bina Aksara.

Iskandar, (2008) Metode Penelitian pendidikan dan Sosial Kuantitatif dan Kualitatif, Jakarta: Gaung persada.

K.Pemradi, (1996), Pemimpin dan kepemimpinan Dalam Menajemen, Jakarta: Rineka Cipta.

Margono. (2005) Metodologi

Penelitian Pendidikan, Jakarta: PT.

Rineka Cipta. 
Mukhtar, dkk, (2001), Sekolah

Berprestasi, Jakarta: Nimas Multima.

Nana Syaodih Sukmadinata, dkk (2006), Pengendalian Mutu Sekolah Menengah (Konsep, Prinsip, dan Intsrumen ), Bandung: Retika Aditama.

Nurul Zariah, (2006), Metodologi Penelitian Sosial dan Pendidikan Teori dan Aplikasi, Jakarta: Bumi Akasara.

Oemar Hamalik, (2006) Menajemen Pengembangan Kurikulum, Bandung: Remaja Rosda Karya.

Oteng Sutisna, (1983), Administrasi Pendidikan Dasar Teoritis Untuk Praktek Profesional, Bandung: Penerbit Angkasa.

Redaksi Sinar Grafika, (2006), Undang-undang Sisdiknas sistem Pendidikan Nasional ) 2003 ( UU RI RI. NO. 20 Th. 2003 ), Jakarta: Rajawali Pers.

Saiful Sagala, (2006), Menajemen Berbasis Sekolah \& Strategi Memenangkan Persaingan Mutu, Jakarta: Nimas Multima.

Sanapiah Faisal. (1990) Penelitian Kualitatif Dasar-dasar dan Aflikasi: Malang YA3.

Sugiyono, (2007), Peneltian

Kuantitatif Kualitatif dan $R \& D$,

Bandung: Alfabeta.
Suharsimi Arikunto. (1983) Prosedur Penelitian Suatu Pendekatan praktek, Jakarta: Rineka Cipta.

Surawan Martinis, (2001), Kamus Kata Serapan, Jakarta: Gramedia Pustaka Utama.

Umar Husein. (2005) Metode Penelitian Untuk Skripsi dan Tesis Bisnis, Jakarta: Rajagrafindo Persada.

Wahjosumidjo, (2007),

Kepemimpinan Kepala Sekolah, Jakarta: Rajawali Pers. 